\title{
GRA PROSPECTUS: OPTIMIZING PROTECTED AREAS FOR CONSERVATION, SEPTEMBER 2001
}

By David Halsing and Richard Bernknopf

Open-File Report 02-67

2002

U.S. Department of the Interior

U.S. Geological Survey 


\section{INTRODUCTION}

This Open-File Report is being submitted in accordance with Geographic Research and Applications (GRA) Prospectus guidelines. It is intended to be a report on the research activities and progress made in the third and fourth quarters of fiscal year (FY) 2001, an extension of the literature review in the March 2001 Open-File Report, and an outline of the next steps that will be taken in the project. This report is organized in eight sections. Section 1 gives a general update and describes the progress made by our collaborators and research partners. Section 2 reviews important literature found since the last report and explains how we intend to use it. Sections 3 through 6 describe major project stages and the research products that are being developed for each of them. In each section, we first report achievements and then outline the next steps for each project stage. Section 7 elaborates on the framework for the Land Use Portfolio Model that was developed for the previous Open-File Report. Section 8 contains the references for this paper and other selected references.

\section{SECTION 1: UPDATE AND COLLABORATOR PROGRESS}

The strategy for this project was for the U.S. Geological Survey (USGS) researchers to use informationincluding ecological, geographic, and socioeconomic data-from protected areas created by Conservation International (CI) as case studies to develop a suite of analytical tools and methods to improve the site selection and management of tropical protected areas. The research products would be usable by managers of those areas, but they would also be adaptable and transferable to other protected areas that exist or will be created in the future. Therefore, much of our research depends on the activities of our research partners. Here, we report on their recent accomplishments.

In June 2001, the Field Museum of Natural History (FM) and Hardner and Gullison Associates (HGA) working in conjunction with a Peruvian conservation group called the Asociación Peruana par la Conservación Naturaleza (APECO) — completed the establishment of Parque Nacional Cordillera Azul (PNCA) in the Biabo region of Perú. Unlike the "conservation concession" approach that was described in the original proposal and that will be characteristic of efforts by another collaborator, CI, this protected area was established as a true national park. Scientific research and some tourism will be permitted there, but resource extraction will not. PNCA continues to be Peruvian public lands but, unlike most national parks, was established and will be managed with private funds (J. Hardner, oral communication, 2001). The park is over 1.1 million hectares in size and is located in a transition zone between the Amazon Plain to the east and the foothills of the Andes to the west. The FM completed a Rapid Biological Inventory (RBI) of the area, published a detailed report of the geology, geography, ecology, and biology of the park, and outlined the land use and threats arising from human activities around the PNCA (Alverson and others, 2001).

The FM also completed and published an RBI of the Pando region of Bolivia (Alverson and others, 2000), where $\mathrm{CI}$ is currently negotiating the terms of another protected area. For their part, $\mathrm{CI}$ and HGA have also neared completion of a concession-based protected area in Guyana. Data from that site should begin arriving in early 2002.

The Ecosystem Science and Technology Branch of the National Aeronautics and Space Administration (NASA) Ames Research Center has also signed on as a collaborator. Dr. Liane Guild, tropical systems ecologist and remote sensing scientist, has agreed to provide assistance and technical expertise in procuring and analyzing remote sensing imagery of these protected areas. To satisfy NASA's full-cost accounting procedures, this project's budget request for FY 2002 included funding for Dr. Guild's participation. Her cooperation will be vital to the remote sensing aspects of the research products that are described in Sections 3 through 6.

\section{SECTION 2: ADDITIONAL LITERATURE REVIEW}

Since the March 2001 Open-File Report was submitted, we have continued to review the literature on creating and managing protected areas, measuring and ranking biodiversity, prioritizing conservation efforts, analyzing and

Any use of trade, product, or firm names is for descriptive purposes only and does not imply endorsement by the U.S. Government. 
managing risk, determining the economics of conservation, and exploring remote sensing technologies as used in detecting land use/land cover change in tropical forests. Here, we summarize three papers that provide strong conceptual guidance for our project, so that we can refer to them in Sections 3 through 6 of this report. Section 8 lists other background research that provides data or support but is not so integral that it needs to be described here.

\section{Annotated References}

Cassel-Gintz, M., and Petschel-Held, G., 2000, GIS-based assessment of the threat to world forests by patterns of nonsustainable civilization-nature interaction: Journal of Environmental Management, v. 59, p. 279-298.

- This paper details a way of using spatial information in a geographic information system (GIS) format to systematically assess and rank the risks of forests for anthropogenic degradation or destruction. Their study is conducted at a global scale and with less detail than we will need to manage risks that face a specific area, but their method seems readily adaptable to our purposes. In short, the method consists of developing a list of narrowly defined threats (that is, land clearing for agriculture, clear cutting for timber sales, poaching of wildlife) and using a GIS to demonstrate and quantify aspects of the dynamics that are involved in each. The goal is to create a relative-risk ranking of each area based on a combination of its vulnerability and the value of its resources of land uses other than protected forest. Logging for timber sales, for example, is most likely in areas that have high vulnerability (good roads and/or near a river, little slope) and high desirability for loggers (many board-feet per acre, high market price per board-foot). Even a readily accessible area will not face this threat if it is grassland or scrub, but it might face overgrazing or urban development threats. The vulnerability and the desirability of each area combine to demonstrate the relative risk of each area and can point out areas where conservation efforts, resources, and dollars should be directed. We are developing a list of threats and measures of both vulnerability and desirability for the case study areas and will soon begin setting up the GIS to support this type of analysis.

Ramirez-Sanz, L., Alcaide, T., Cuevas, J.A., Guillen, D.F., and Sastre, P., 2000, A methodology for environmental planning in protected natural areas: Journal of Environmental Planning and Management, v. 43, no. 6, p. 785-798.

- The authors develop a GIS-based method for prioritizing areas for protection. A protected area was divided into a matrix of grid cells, each of which was evaluated in terms of four components/resources: vegetation, fauna, soil, and landscape. Each cell was ranked in terms of its "natural value" and "state of conservation." The rankings for these components were scored on the basis of information extracted from GIS layers - things like slope, soil maturity, number of bird species, and forest seral stage, for example. This method allows a quantitative assessment of areas for protection. Cells with high value and low protection would be first, while areas with low value that were not at risk would not be aggressively defended. We are currently investigating ways to apply this system to tropical forests. We will have to develop a similar system to assess both the ecological value and the level of threat that various parts of the protected areas face.

Balmford, A., Gaston, K.J., and Rodrigues, A.S.L., 2000, Integrating costs of conservation into international priority setting: Conservation Biology, v. 14, no. 3, p. 597-605.

- The authors investigate different methods of including costs of conservation in the allocation of conservation efforts among countries. Using numbers of mammal species and estimates of costs to adequately protect reserves in 111 countries, the authors compared different methods of measuring "protection per dollar spent." They compared priority ranking on the basis of absolute species richness, richness for endemics, ratio of total species richness to cost, and ratio of species endemism to cost. They also ran a linear program to maximize species coverage at a range of cost levels. Since cost-effectiveness of conservation is the central goal of this project, this approach is potentially very useful for us. We would have to adapt it from using countries as the unit of analysis to using grid cells, watersheds, or some other unit. We would also want to substitute some other measure of biological/ecological value instead of simply numbers of mammal species.

\section{SECTION 3: REMOTE SENSING AND GEOGRAPHIC INFORMATION SYSTEM}

\section{DATABASE}

One of the first steps in this project is the creation of a database in which to manage and analyze all the GIS information and remote sensing imagery that have been and will be developed as work progresses on the PNCA. This database is not simply a storage site for the information. Rather, it will serve a range of purposes to our research partners and the agencies responsible for managing the protected areas that have been or will be established. 
First, the principal investigators at the USGS will use this GIS and remote sensing (RS) data in various statistical and optimization models. This database currently holds baseline GIS/RS information on the PNCA and its surroundings. As the literature review above describes, most of the prioritization and cost-effectiveness analyses we are using as conceptual frameworks for our research take place in a GIS/spatial analytical context, so working with our partners to collect and organize this information was an important first step.

The database currently includes Landsat thematic mapper (TM) imagery from 1999, 1996, and 1989 (four contiguous scenes per year) that we are using to conduct a land use/land cover change analysis of the area surrounding the park for that time period. We have created mosaics of the scenes and are currently experimenting with vegetation classification algorithms.

The next steps are to quantify the rate of change and locate the areas in which land use/cover change has occurred. We have also ordered several higher resolution SPOT scenes that we will use to assess what gains this more detailed information can bring. This analysis is a product in itself and will be submitted for publication, but the information in the imagery will also be a key component of other project stages, as described in Section 4.

Our research collaborators will also be making use of the GIS/RS database in several important ways. The protected-area managers will be acquiring annual remote sensing imagery to verify that the protected areas have been maintained as such. As was described in the original project proposal, the "conservation concession" approach includes annual payments to the host countries and communities pending such verification. The imagery that they acquire for this purpose can also be used to direct management, enforcement, or mitigation efforts to areas in and around the park where degradation is occurring. While we will be building tools to improve the efficiency of these efforts, the park managers will also be using the database to develop and implement baseline management strategies. We will also be using this annual imagery to conduct ongoing land use/land cover analyses, measuring changes in the patterns and dynamics of land use around the park in the years after its establishment. This will result in another publication.

After its initial establishment, the database will be updated with information collected regularly by park rangers and/or scientists working in the protected areas. They will submit these updates to the principal investigators, who will update the database and use the information to conduct repeated, more detailed analyses. Our collaborators and park managers are currently developing the procedures for the field surveys that will be used to provide these database updates.

Another long-term goal of the GIS/RS database subproject will be to link it to the World Wide Web using ESRI's ArcIMS software. This program allows simple GIS functions and applications to be performed on the Web without requiring the end user to purchase GIS software or have special training. The park managers will be able to access the database — updated with annual remote sensing and periodic field-level inputs—and adapt their management strategies quickly and wisely. Putting the GIS/RS information on the Web also makes it accessible to the general public. Increasing public awareness of conservation efforts, biodiversity protection, and USGS cooperation with nonprofit organizations is a positive side benefit of this project.

\section{SECTION 4: COST-EFFECTIVENESS OF REMOTE SENSING}

The GIS/RS database that we have created will also form the foundation for a study of the cost-effectiveness of remote sensing data. Since financial resources for conservation management are scarce, making the most efficient use of those resources is crucial. One area where potential gains in efficiency can be made is in the remote sensing imagery that is acquired for verification and management purposes. Thus, we have begun a cost-effectiveness analysis of the various RS technologies.

The default imagery for the conservation of large areas has been Landsat TM, and it appears to work reasonably well for this purpose. But we are investigating whether the informational gains from augmenting or replacing it with other types of imagery (or changing the frequency of acquisition) would justify the increased costs of doing so.

Our methodology for this analysis is fairly simple. We are investigating the spatial, spectral, and temporal resolutions of different RS technologies to assess the threat-specific ability to detect, recognize, and analyze susceptibility to different threats. By combining these abilities with the likelihood of the various threats, we can develop an index of the utility of each technology in monitoring the protected area. This yields a measure of "effectiveness," which can be compared with the known costs of acquiring the data. 
Several types of remote sensing technology (SPOT, for example) will be investigated singly and in combination with others, particularly Landsat TM, to see if any cost-effectiveness gains can result from this combination. We wish to determine at which point increased-resolution data do not lead to substantial new discrimination of features of interest on the ground. We are also investigating whether targeted or random higher resolution imagery might bring further efficiency gains.

To date, we have begun acquiring imagery and compiling the costs and specifications of each. We are developing the list of threats and the spatial scale at which each takes place and are beginning to work on the utility index.

\section{SECTION 5: ANALYSES AND METHODS FOR IMPROVING MANAGEMENT}

Bruner and others (2001) found that parks could be effective at preventing human impacts, provided that adequate management practices (this is, patrols, education) could be employed. This project stage involves conducting a set of analyses for improving the efficiency and cost-effectiveness of those management procedures in protected areas. We will do this by developing risk assessment methods and by prioritizing areas for increased enforcement or mitigation activities.

In the literature review section, we discussed a risk assessment strategy developed by Cassel-Gintz and PetschelHeld (2000) and mentioned briefly our plans to adapt it from a global- to a landscape-level scale, and to include more detail specific to the area in question. This paper provides a conceptual framework for how to measure threatspecific risks to an area (for example, threats from land clearing for cash-crop agriculture vs. for grazing vs. for timber). We also summarized a paper by Ramirez-Sanz and others (2000) that contains a method for using information typically available in a GIS to rank the ecological values of an area on the basis of a suite of characteristics. Finally, we discussed work by Balmford and others (2000) that sought to integrate the costs of conservation into the areas that were selected for protection.

The goal of this project stage is to apply and integrate these three approaches. We are currently developing a list of threats specific to the first case study area, the PNCA. We are also beginning to use the GIS information and the remote sensing imagery we have acquired for previous project stages to create baseline measurements of the biophysical factors that can measure those risks. Some of these factors include presence and quality of roads, extent of navigable rivers, suitability of the land for grazing or crop agriculture, distance from population centers, degree of slope, and so on. Each of these factors can be assessed, quantified and tracked in a GIS format, and used to develop a measure of vulnerability.

We are also beginning to develop a system for ranking the ecological/biological values of different regions of the park and its surroundings. This system will be similar in design to the one presented by Ramirez-Sanz, but with variables and scores that are adapted to the local area. Factors here include species richness and rarity, continuity of habitat, proximity to park borders, and others.

When we have these systems for measuring both the risk factors and the ecological/biological values of each subregion within the protected-area, we can begin prioritizing them for enhanced monitoring, enforcement, and, if necessary, mitigation efforts. Particularly when combined with Balmford's analysis of different methods for prioritization, this project stage will produce a very useful set of methods and tools for managing the risks of protected area failure. We anticipate that park managers will use these tools to improve management of the PNCA, but also that the methods will be replicable products that $\mathrm{CI}$ and other conservation agencies could adapt to their reserves by collecting similar information (spatial and otherwise) to that which we used.

Finally, in Section 3, we described the GIS/RS database we have established. As management activities proceed in PNCA, we intend to update the GIS with reports from workers in the field and to reassess the risks and values of various sections of the park. Once the framework is in place and the metrics are developed, adding new information will be very rapid and simple. This will provide a tight feedback between management activities and their effectiveness, which should allow standard practices to evolve and improve. A similar, though less frequent, dynamic is expected when we update the database with annual remote sensing imagery. 


\section{SECTION 6: SITE SELECTION OPTIMIZATION STUDY}

Though this project phase was the focus of the original proposal, it became clear when detailed work plans were being developed that this larger set of research goals would be met more thoroughly and efficiently by reversing the order of research. We initially planned to develop a model for optimizing the site-selection of protected areas first, and tools for improving the management strategies after that, but the initial case study areas had already been established and site selection improvements would only be of use to future sites. Further, our research partners expressed a more immediate interest in tools to improve their nascent management plans. Finally, many of the subprojects discussed already in this report develop useful components of this larger optimization model.

The effort to date on the site-selection optimization models has been to adapt the Western Geographic Science Center's Land Use Portfolio Model (LUPM) to this project (Bernknopf and others, 2001). Since PNCA already exists, we plan to use the LUPM in a hypothetical site-selection exercise. We will posit, for example, that the entire area that is now PNCA was available to a conservation organization like CI for inclusion into a protected area, but that, because of budgetary or other constraints, the organization had to choose some subportion of the region for protection. Since we have large amounts of data on the park, we will develop the decision framework using the LUPM to investigate the environmental and economic tradeoffs involved in choosing subsections of the area for protection. Below is a description of how the LUPM can be applied to site selection in the PNCA. On the basis of this demonstration, the decision framework will then be exported to other areas as adequate input information becomes available.

In fact, this demonstration, or what-if scenario, is likely to be close to actual situations that will occur in the future. PNCA is an extremely large protected area, and normally CI would not be able to procure such a large stretch of land to include in a conservation concession. However, the Peruvian Government was eager to demonstrate its commitment to conservation and made it available at a reduced cost in exchange for the area being made a national park, rather than a conservation concession (J. Hardner, 2001, oral communication). Typically, in setting up concession-based areas, CI will be faced with higher prices, smaller protected areas, and the prospect of weighing tradeoffs between competing values and risks. Thus, the model from this case study area will be useful.

\section{SECTION 7: THE LAND USE PORTFOLIO MODEL}

A goal of any decision support system (DSS) is to use the best science and apply it in a context for decisionmakers. The LUPM integrates available scientific information by placing it in a decision framework that has relevance to decisionmakers (Bernknopf and others, 2001). The LUPM is a portfolio-based approach to investment decisions in land uses at regional (or landscape) scale, such as maximizing biodiversity preservation. The LUPM allows the decisionmaker to compare the spatial and temporal allocation of lands within a geographic boundary. Within the LUPM, current land uses are termed assets and have both a stock value (value of natural or anthropogenic capital) and a flow value (derived from the dividend or services provided by the stock).

Investments in protection, mitigation, and/or enforcement are modeled as different risky assets. A particular management plan represents a portfolio. The results of decisions and actions associated with preserving a protected area benefit local communities, visitors, landowners, governments, conservation managers, and donors. These stakeholders become the "investors." The investment outcome is losses avoided to ecosystem function, services, and integrity (or attributes). The stakeholders are assumed to desire the greatest possible return on investment, but they are uncertain whether a loss of ecosystem attributes will occur during a fixed time period.

The LUPM approach can be used to provide a suite of portfolios that are hypothetical land use allocations and protection strategies that stakeholders can consider and then use to help make land use choices according to their own preferences. For example, one solution of the LUPM can prioritize land for acquisition on the basis of human recreational services and biodiversity, while another solution can prioritize land for multiple-use development. The two policies are displayed and analyzed in detail using a GIS.

The LUPM uses regional datasets with minimal field study and thus avoids the need for site-specific evaluations. Land use threat zones are developed at a reasonable level of resolution for the characterization of risk. The approach divides the region into locations $k \in K$, each belonging to one of several land use threat zones $h \in H$, where locations belonging to the same zone each have the same probability of damage to ecosystem attributes. The 
variable $h$ represents an ordinal ranking of the characteristics that define the susceptibility of ecosystem disturbance. The word location refers to the smallest geographic unit of analysis, which may be grid cells, parcels, or watershed units.

The variation in threats to biodiversity or other environmental resources can be represented by landscape features and functions that have an impact on the existing land use, such as impermeable coverage, roads, logging, and agriculture. The probability of damage or loss of attributes must reflect the probability that a specific location in a particular land use threat zone will experience a specified loss. Let $q_{h}$ be defined as the joint probability of experiencing a disturbance $p(H A Z)$ and the probability $p_{h}(F A I L)$ of the disturbance resulting in loss of environmental values at any location in landuse threat zone $h$ :

$$
q_{h}=p_{h}(F A I L) \cdot p(H A Z)
$$

The LUPM approach to regional risk assessment begins by defining a protected area as a set of $K$ contiguous geographic locations. Each location $k$ is assigned to a land use category $j \in J$ and a land use threat zone $h$. In general, the term security refers to any possible investment vehicle where expenditure is made and a future receipt or dividend is expected. Here, a security type $i \in I$ refers to an investment in protection in a location belonging to a unique combination of a land use type $j$ and a threat zone $h$. By definition, all locations of the same security type are in the same hazard zone, meaning that all locations of the same security type have the same probability of loss. Therefore, $p_{i} \equiv p_{h}$ and $q_{i} \equiv q_{h}$.

The land use portfolio, like an investment portfolio, can contain assets with a wide range of values and risks. Locations of the same land use type within the same threat zone can have a wide range of biological values. Let $V_{k}$ represent the value of location $k$ or an average value that can be used for all locations. The average value of a location of security type $i$ is defined as $\bar{V}_{i}$, the sum of all the values of locations of type $i$ divided by $K_{i}$, the number of locations of that type. For each location, only one of two possible future states of nature $s$ can occur; $s_{k}=1$ if the ecosystem is violated and causes loss of value to a location, and $s_{k}=0$ if it does not.

The return from protection in a particular location is defined as the value of the environmental attributes that would have been lost if the protection had not taken place. The probability of damage therefore determines the distribution of possible returns from investment in protection. The benefits of protection come with a cost. The cost of protection comes from land price plus management and enforcement costs and is assumed to vary by security type. Define $C_{i}$ as the cost of protecting a cell of security type $i$. The returns from investment for all locations of type $i$ in each state of nature are an outcome for a location $O_{k}$ :

$$
O_{k}= \begin{cases}\frac{0-C_{i}}{C_{i}}=-1 & \text { if } s_{k}=0 . \\ \frac{\bar{V}_{i}-C_{i}}{C_{i}} & \text { if } s_{k}=1 .\end{cases}
$$

The outcome associated with $s=0$ occurs with a probability of $1-q_{i}$, and the outcome associated with $s=1$ occurs with a probability of $q_{i}$.

The possible outcomes under different states of nature and their associated probabilities form a probability distribution of the return from investing in a particular security type. The expected rate of return of a security $i$ is the sum of the rates of returns for the outcomes weighted by their probabilities:

$$
E_{i}=\left(\frac{\bar{V}_{i}-C_{i}}{C_{i}}\right) q_{i}+(-1)\left(1-q_{i}\right)=\frac{\bar{V}_{i} q_{i}}{C_{i}}-1
$$


The variance is equivalent to the sum of the squared differences between the outcomes in each state and the expected returns, weighted by their probabilities:

$$
\sigma_{i}^{2}=\left(\frac{\overline{V_{i}}-C_{i}}{C_{i}}-E_{i}\right)^{2} q_{i}+\left(-1-E_{i}\right)^{2}\left(1-q_{i}\right) .
$$

Define the total amount of money invested in a portfolio as budget $B$. A portfolio can be described by the proportion $\alpha_{i}$ of the budget invested in each security type $i$ :

$$
\sum_{i=0}^{I} \alpha_{i}=1
$$

The expected return for a given portfolio $A$ is the weighted average of the returns for each security multiplied by their proportions:

$$
E_{A}=\sum_{i=0}^{I} \alpha_{i} E_{i}=\sum_{i=0}^{I} \alpha_{i}\left(\frac{\overline{V_{i}} q_{i}}{C_{i}}-1\right) .
$$

The variance of returns from a portfolio depends on the standard deviations of its component securities, the proportions invested in each security type, and the correlation of returns from mitigation in one location to another. Variance in the return is attributable to sources such as the susceptibility of the ecosystem to disruption, whether or not the land threat event occurs, and the variation in the value of properties of the same security type.

$$
\begin{aligned}
& \sigma_{A}^{2}=\left(\sum_{i=0}^{I} \frac{\alpha_{i} \bar{V}_{i} p_{i}}{C_{i}}\right)^{2} p(H A Z)(1-p(H A Z))+\frac{1}{B}\left(\sum_{i=0}^{I} \frac{\alpha_{i} \bar{V}_{i}^{2} p_{i}\left(1-p_{i}\right)}{C_{i}}\right) p(H A Z) \\
& +\frac{1}{B}\left(\sum_{i=0}^{I} \frac{\alpha_{i} \sigma_{V_{i}}{ }^{2} p_{i}}{C_{i}}\right) p(H A Z) .
\end{aligned}
$$
return.

Choices are modeled as portfolios that can be described and compared by the distributions of their rates of

A stakeholder coalition is assumed to have an existing level of wealth, $W_{0}$, which is equal to a protection budget $B$ plus the sum of the biological values in the geographic area:

$$
W_{0}=B+\sum_{i=0}^{I} \overline{V_{i}} K_{i} .
$$

Budget funds come from external grants that are contingent on their use for protection. The stakeholders then choose how to allocate the budget among the available security types. Each allocation results in a unique conservation scenario expressed as a portfolio. Each portfolio's expected return and standard deviation can be calculated and different portfolios can be compared. Because the region has a geographic boundary, there are a limited number of "shares" of each security type available. A portfolio can be described by the fraction of locations in each security type, $f_{i}$, that would be protected under that strategy:

$$
f_{i}=\frac{\alpha_{i} B}{C_{i} K_{i}} .
$$


A forest health and wealth outcome is dependent on how many locations experience each state of nature. A protection policy positively affects this value by reducing risk of loss of ecosystem resources from specified locations. The expected wealth outcome $E W$ for a given portfolio $A$ involves subtracting from $W_{0}$ both the budget and the expected losses that remain for all the locations that were not protected under a specific scenario. The possible wealth outcomes from a particular portfolio choice for each of the two possible states of nature are calculated as follows:

$$
E W_{A}=W_{0}-B-\left(\sum_{i=0}^{\mathrm{I}} \overline{V_{i}} K_{i} q_{i}\left(1-f_{i}\right)\right)
$$

Expected wealth also has a variance:

$$
\begin{aligned}
& \sigma_{A}^{2}=\left(\sum_{i=0}^{I} \bar{V}_{i} K_{i} p_{i}\left(1-f_{i}\right)\right)^{2} p(H A Z)(1-p(H A Z))+\sum_{i=0}^{I} \bar{V}_{i}^{2} K_{i} p_{i}\left(1-p_{i}\right)\left(1-f_{i}\right) p(H A Z) \\
& +\sum_{i=0}^{I} \sigma_{V_{i}}{ }^{2} K_{i} p_{i}\left(1-f_{i}\right) p(H A Z) .
\end{aligned}
$$

For a given budget, the expected wealth outcomes that result from different conservation scenarios can be compared. The goal is to aid the investor (that is, a donor and a conservation organization) in deciding upon a set of land purchases and spatially specific management investments that maximize expected biological benefits while minimizing the uncertainty of the projected outcome. The LUPM could be constructed to solve the constrained optimization problem:

$$
\min _{k}\left[E W_{A}-\sigma_{A}\right]
$$

subject to: $\quad k>0$

$$
B \geq 0
$$

The next step in this part of the project is to complete the adaptation of the LUPM and to conduct a proof-ofconcept demonstration in the PNCA.

\section{SECTION 8: SELECTED REFERENCES}

Alverson, W.S., Moskovits, D.K., and Shopland, J.M., eds., 2000, Bolivia-Pando, Rio Tahuamanu—rapid biological inventories report 1: Chicago, III., The Field Museum.

Alverson, W.S., Rodriguez, L.0., and Moskovits, D.K., 2001, Perú-Biabo Cordillera Azul—rapid biological inventories report 2: Chicago, III., The Field Museum.

Aspinall, Richard, and Pearson, Diane, 2000, Integrated geographic assessment of environmental condition in water catchments: linking landscape ecology, environmental modeling and GIS: Journal of Environmental Management, v. 59, p. $299-319$.

Balmford, A., Gaston, K.J., and Rodrigues, A.S.L., 2000, Integrating costs of conservation into international priority setting: Conservation Biology, v. 14, no. 3, p. 597-605. 
Barbier, E.B., and Burgess, J.C., 1997, The economics of tropical forest land use options: Land Economics, v. 73, no. 2, p. $174-195$.

Bernknopf, R.L., Dinitz, L., Rabinovici, S., and Evans, A., 2001, A portfolio approach to evaluating natural hazard mitigation policies: an application to lateral-spread ground failure in coastal California: International Geology Review.

Bruner, A.G., Gullison, R.E., Rice, R.E., and de Fonseca, G.A.B., 2001, Effectiveness of parks in protecting tropical forest biodiversity: Science, v. 291, p. 125-128.

Cassel-Gintz, M., and Petschel-Held, G., 2000, GIS-based assessment of the threat to world forests by patterns of nonsustainable civilization-nature interaction: Journal of Environmental Management, v. 59, p. 279-298.

Church, Richard, Stoms, David, and Davis, Frank, 1996, Reserve selection as a maximal coverage locating problem: Biological Conservation, v. 76, no. 2, p. 105-112.

Ferraro, P.J., and Simpson, R.D., 2000, The cost-effectiveness of conservation payments: Resources for the Future-Discussion Paper 00-31: Washington, D.C.

Heinen, Joel, 1996. Human behavior, incentives, and protected area management: Conservation Biology, v. 10, no. 2, p. 681-684.

Howard, P.C., Davenport, T.R.B., Kiyengi, F.W., Viskanic, P., Baltzer, M.C., Dickinson, C.J., Lwanga, J., Mathews, R.A., and Mupada, E., 2000, Protected area planning in the tropics: Uganda's national system of forest reserves: Conservation Biology, v. 14, no. 3, p. 858-875.

Inamdar, Amar, deJode, Helen, Lindsay, Keith, and Cobb, Stephen, 1999, Capitalizing on nature: protected area management: Science, v. 283, no. 5409, p. 1856-1857.

James, A., Gaston, K.J., and Balmford, A., 2001, Can we afford to conserve biodiversity?: BioScience, v. 51, no. 1, p. 43-52.

James, A., Gaston, K.J., and Balmford, A., 1999, Balancing the Earth's accounts: Nature, v. 40, p. 323-324.

Mendelsohn, Robert, 1994, Property rights and tropical deforestation: Oxford Economic Papers, v. 46, p. 750-756.

Ramirez-Sanz, L., Alcaide, T., Cuevas, J.A., Guillen, D.F., and Sastre, P., 2000, A methodology for environmental planning in protected natural areas: Journal of Environmental Planning and Management, v. 43, no. 6, p. 785-798.

Reid, J.W., and Bowles, I.A., 1997, Reducing the impacts of roads on tropical forests: Environment, v. 39, no. 8, p. 10-35.

Saatchi, S., Agosti, D., Alger, K., Delabie, J., and Musinsky, J., 2001, Examining fragmentation and loss of primary forest in the southern Bahian Atlantic forest of Brazil with radar imagery: Conservation Biology, v. 15, no. 4, p. 867-875.

Sheil, Douglas, 2001, Conservation and biodiversity monitoring in the tropics:

realities, priorities, and distractions: Conservation Biology, v. 15, no. 4, p. 1179-1182.

Skole, David, and Tucker, Compton, 1993, Tropical deforestation and habitat fragmentation in the Amazon: satellite data from 1978 to 1988: Science, v. 260 , p. $1905-1910$. 
Steininger, M.K., Tucker, C.J., Ernst, P., Killeen, T.J., Villegas, Z., and Hecht, S.B., 2001, Clearance and fragmentation of tropical deciduous forest in the Tierras Bajas, Santa Cruz, Bolivia: Conservation Biology, v. 15, no. 4, p. 856-866. 